\title{
CPAP Hardware/Simulation and Control Design for Respiratory Disorders: A Review
}

\author{
Athra'a Sabeeh Mikha ${ }^{1}$, Hadeel K. Aljobouri ${ }^{2}$
}

\section{Authors affiliations:}

1) Biomedical Engineering Department, College of Engineering, Al-Nahrain University, Baghdad, Iraq. eng.athraasabeeh@gmail.com

2*) Biomedical Engineering Department, College of Engineering, Al-Nahrain University, Baghdad, Iraq. hadeel_bme77@yahoo.com

\section{Paper History:}

Received: $7^{\text {th }}$ May 2021

Revised: $9^{\text {th }}$ Oct. 2021

Accepted: $10^{\text {th }}$ Nov. 2021

\begin{abstract}
Continuous Positive Airway Pressure (CPAP) ventilation remains a mainstay treatment for different respiratory disorders. Good pressure stability and pressure reduction during exhalation are of major importance condition to ensure the clinical efficacy and comfort of CPAP therapy. Obstructive Sleep Apnea (OSA) and today coronavirus (COVID-19) are the main two diseases mitigated by the CPAP. This paper introduced a systematic review of the CPAP design in terms of the hardware design, Simulation-based CPAP system, control algorithm, and the measured performance. The accuracy is used as measurement of performance and calculated from the pressure value. The accuracy was compared to the predefined U.S. Food and Drug Administration (FDA)-based threshold value in which it considers this value as a reference. The results related to the modern CPAP devices introduced in this study to explain the accuracy of experimental CPAP. These were compared with a commercial CPAP devices. Also, it was revealed how the results coincide with the error ratio defined by the FDA as an evaluation measurement. The FDA error ratio determines the performance of the optimized CPAP device. This work is the first review that presented the knowledge about engineering design of the CPAP system, so it will be the first in the literature.
\end{abstract}

Keywords: COVID-19, CPAP Hardware Design, CPAP Model Simulation, Obstructive Sleep Apnea (OSA), PID Controller.

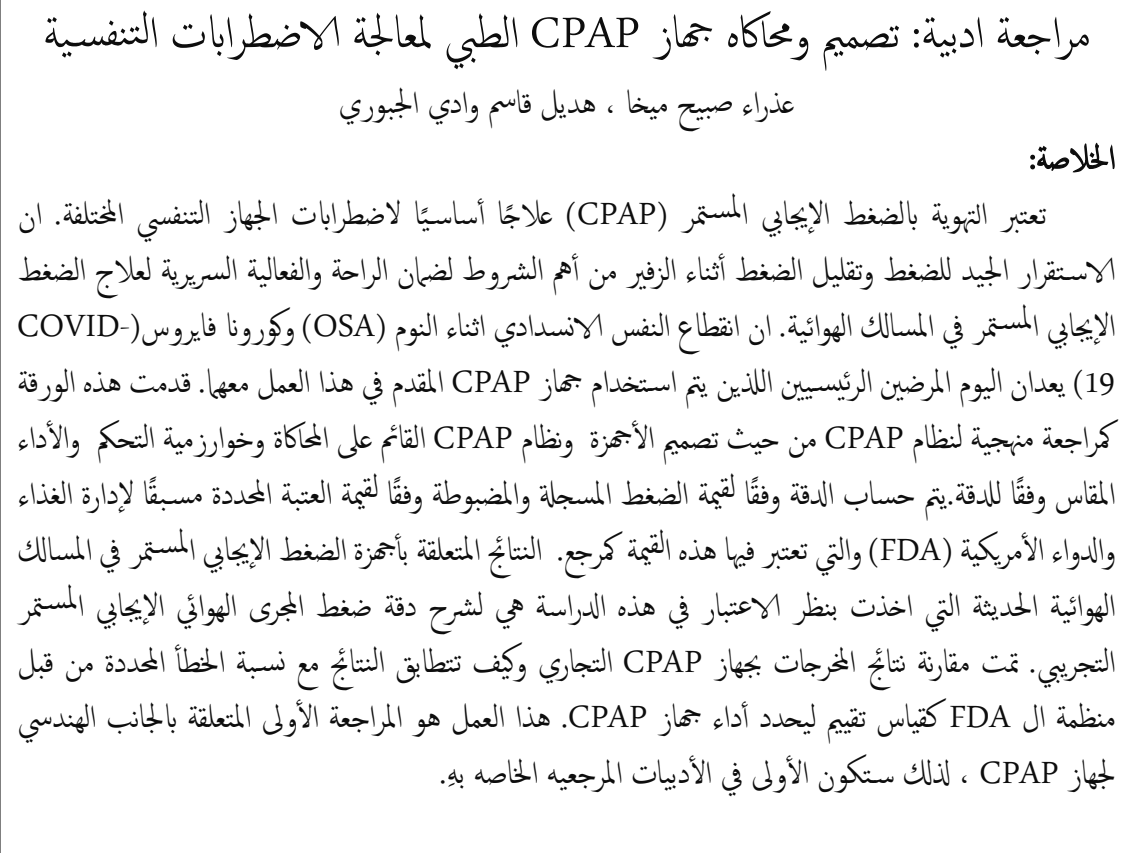

\section{Introduction}

Obstructive Sleep Apnea (OSA) describes as a chronic and heterogeneous disorder that cause early mortality, stroke, and cardiovascular disease (CVD). OSA is explained as an apnea-hypopnea measure. It is an index of OSA severity that merges apneas (stops in

NJES is an open access Journal with ISSN 2521-9154 and eISSN 2521-9162

This work is licensed under a Creative Commons Attribution-NonCommercial 4.0 International License 
breathing) and hypopneas (partial obstructions in breathing) correlate with hypoxemia. However, sleep disorder such as the oxygen nadir, and arousal frequency. Besides the clinical symptoms might cause stroke and CVD in OSA [1]. It is characterized by the recurrence of the complete or incomplete collapse of the upper airway during sleep. This might occur in disorders of normal sleep rhythm [2].

Coronavirus Disease 2019 (COVID-19) has become one of the serious problems provoking severe respiratory disorders. It has been spread fast worldwide since it was first appeared in Wuhan, China, in December 2019. The World Health Organization (WHO) called the new epidemic disease Coronavirus Disease [3]. The Coronavirus is a member of a viral family that might induce various symptoms. For instance, fever, pneumonia, lung infection, and breathing difficulty, etc... [4]. Coronavirus 2019 and obstructive sleep apnea syndrome diseases are both identified as respiratory disorder that obliged immediate medical intervention. In this domain, many researchers have tried different methods to resolve this kind of disorders. One of the methods that helped patients to feel more comfortable during the respiratory cycle involved the usage of CPAP devices. CPAP devices are considered as non-invasive techniques assisting patients having this kind of respiratory disorders [5][6]. With patients of Obstructive Sleep Apnea OSA, the CPAP (i) decreases unnecessary daytime sleepiness, (ii) reduces blood pressure of patients with hypertension, and (iii) improves cognitive function and lifestyle. All of these points assisted reducing the chance of cardiovascular morbidity and mortality [7]. The treatment of OSA with CPAP was first described by Sullivan et al. in 1981. The key idea behind using the CPAP is to use a nasal mask functions as a pneumatic splint to maintain upper airway patency, moving the soft palate anteriorly [8].

CPAP device produces a constant flow of oxygen in a specified pressure measured in $\mathrm{cmH}_{2} \mathrm{O}$. This pressure must remain constant in both inspiration and expiration. By applying the constant pressure of CPAP device, the lung's airway pressure would be guaranteed. Moreover, the pressure stability of CPAP would also prevent the collapse of alveolar. This implies that the increase of lung volume to enable its capacity to be blown. After that, the gap between the alveolar and the blood vessels would be decreased to enhance gaseous exchange [9]. The Initial CPAP settings in severe COVID-19 cases recommended by [6] are $10 \mathrm{cmH}_{2} \mathrm{O}$ and $60 \%$ oxygen. After defining CPAP's parameters, a tight fitting-mask or hood is needed to be adapted during the use of CPAP device in severe COVID-19 cases to ensure the best performance [6].

CPAP device includes a pump that blows air into the patient's mouth, nose or one of them during sleep to keep the airway open and to avoid obstructions. A hose and mask are attached to patient's face so as to connect the pump to the patient's face [9] .The CPAP system consists of (i) microcontroller such as microprocessor and Arduino, (ii) sensors for pressure and temperature measurements, (iii) motor controller, (iv) tube and mask, (v) motors that are integrated with blower. The brushless DC or the permanent magnet motors are some examples of the CPAP motors[10][13].

The main aim of this review paper is to describe the CPAP system mechanism in terms of the design and its control algorithms. Furthermore, this paper would focus on explaining the hardware design of CPAP that incorporates the motors, and microcontrollers. This paper would consider the allowable U.S. Food and Drug Administration error ratio as an evaluation criterion that determines the performance of the optimized CPAP device. A series comparison among different CPAP devices will be conducted.

This work is the first review that presented the knowledge about the engineering design of the CPAP system. However, [14][15] were review papers highlighting the performance of the CPAP system in terms of medical and physiological aspects.

This paper is designed as follows; in section (2) a theoretical background is given to discuss the mechanism of CPAP and its components. In section (3) a comparison is made of many different CPAP system.

\section{Related work}

The presented work divided into two main sections, the historical background and modern CPAP design.

\subsection{Historical Background}

The CPAP devices have gone through several developments overtime until it reached its current form. The beginning was in 1981, where a Sullivan, Isaa, used CPAP device to treat five patients with severe Obstructive Sleep Apnea. The schematic diagram of the first CPAP contained two smooth plastic tubes where their shape fit with each naris. These tubes secured to the patient's face after inserted to the wide-bore. The silicone rubber run over patient's nares and nose for more convenience. The wide-bore tube processes double-sided terminals. One of these two terminals was connected to a vacuum cleaner blower motor, and the other terminal was narrowed away from the patient with mechanical resistance. This design included two types of catheters one was used to measure the pressure and the other one was used to measure the airway $\mathrm{CO}_{2}$. Both catheters were inserted inside the nasal tube [16]. Figure (1) shows the first design of Sullivan's CPAP system for the severe OSA patients.

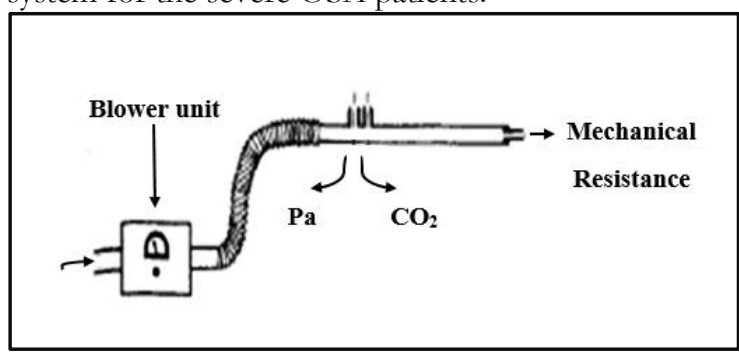

Figure (1): The first design of Sullivan's CPAP system (1981).

Later, in 1991 A. Braschi and G.Iotti presented three designs of CPAP ventilator system depended on 
the function of CPAP that was used. Continuous flow, Demand flow, and mixed systems.

Continuous flow systems are straightforward, it is composed of a set of parts located in sequence where a predefined flow of fresh gas running. Through a Ypiece, the gas is provided to the patient and any extra gas is ventilated throughout the patient's exhaled gas. At the end of the circuit Positive End Expiratory Pressure (PEEP) valve was mounted. It interacts with the gas flow to generate a positive pressure. Different ways can be used to assemble the basic parts of a gas supply which can be adjusted for flow rate and FP2, gas conditioner for humidification and heating, a PEEP device and a manometer.

Demand flow addresses the simultaneous behavior of a pair valves. One was a demand valve used for inspiration. The other was used for expiration. The generated circuit pressure decrement leads to open the demand valve and to close the expiratory valve while the patient tries to inspire. Despite of some certain delays, the demand valve provides a gas flow that adjusts itself to the patient's demands once was opened. The transitioning from the inspiratory to the expiratory phase when the demand valve get closed while the expiratory valve gets opened. This process comes as feedback to the patient's expiratory demand.

Mixed systems can provide CPAP ventilators. This represents a third type of CPAP devices. In fact, it is a combination of both the demand valve and continuous ventilator. The standard continuous flow system was used to mimic ventilator servo-controlledvalves. In theory, this combination maintained the pros and reduced the shortcomings of both demand flow and continuous technique [17]. After three years, in 1994, Lofaso et.al developed a nasal CPAP device (nCPAP introduced by Sullivan [16]) with servomechanism as a controller to control the pressure and motor speed to ensure constant CPAP pressure delivered for patients with OSA. The servomechanism controller was tested under dynamic and static conditions in order to approve its efficiency based on nasal CPAP performance [18].

To recap, the first machines designed in 1981 were very noisy, heavy, and large. The later designs in 1991 and 1994 provided more needed relief, but they lacked convenience. The early designs like Sullivan's, they even lack for basic comfort characteristics such as humidification which is considered one of the most needed requirements by patients. In old designs, the set pressure was fixed and the system cannot change itself according to the requirements of patients.

In contrast to old machines, the new machines set pressure is variable and adjust itself over time according to the health, weight, age, and stress levels in order to fulfill patient's demands. In addition, contemporary designs become lighter and portable in comparison to the older designs of CPAP systems which were stationary and heavy.

\subsection{Modern CPAP Designs}

In the last two decade, CPAP technology has revolutionary breakthrough. The CPAP devices has become (i) automated, (ii) self-adjustable according to the patient's needs, (iii) able to guarantee a constant pressure level, (iv) easy to set the parameters and control motor speed, (v) easy to observe and examine the outcomes on LCD screens and besides its light weight and portability. The block diagram of the contemporary CPAP system is shown in Figure (2).

Xu et al. in 2014 presented an optimized controller to obtain better synchrony in ventilator synergies. The experiment system was composed of several parameters like (data acquisition, a set of signal collectors, a blower wired with a driver circuit). The related signals were acquired and prepared by a program of an optimized controller written in LABVIEW. Familiar PID controller is guided to a definite pressure spike of $2 \mathrm{cmH}_{2} \mathrm{O}$ higher than inspiratory pressure. However, the controller proposed in that paper can reduce the pressure immediately without a need to pressure spike through switching to the expiration state. Additionally, the Pressure Volume Loop showed the area of the optimized controller was smaller than the conventional PID controller. The principal behind using the optimized Pressure Evaluate Correction Module (PECM-PID) approved that the ventilator can deliver a pressure that matches the actual respiratory cycle of the patient. As the optimized controller has achieved a promising results, it might be used in the future for synchrony [13].

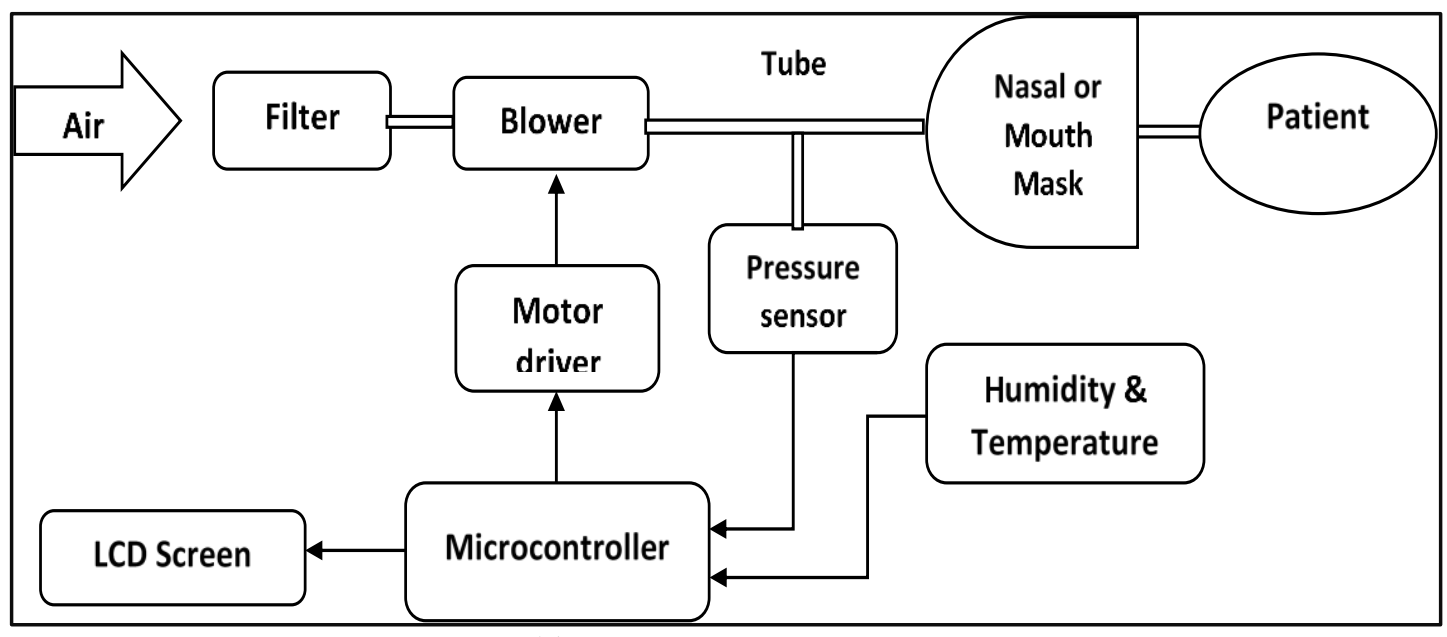

Figure (2): The block diagram of the CPAP system. 
Ximenes et al. in 2014, designed a cheap experimental CPAP device. This device is used for respiratory assistance to be used in a Neonatal Intensive Care Unit (NICU). This device contained three modules: (i) interface, (ii) electro-pneumatic, and (iii) microcontroller. The microcontrollers system is responsible for decisions making. Microcontrollers managed the valves and delivered data from the sensors to the user. It is also responsible for the visual and audio alarms. The system included two microcontrollers. The first, had input variables consisting of signs obtained from five pressure sensors with user alignment buttons. In addition, it controls the closing or opening of the three valves of the system. In turn, these valves are controlled by Pulse Width Modulation (PWM). In other words, this can be done as a software in which square waves are with a frequency of oscillation. As these waves had a lower frequency, the valve powered by this signal order remains almost closed. Consequently, when higher frequency is applied, the valve remains more open. The second microcontroller, had input variables of the recorded values by the user at that moment. The output variables are displayed on the LCD screen. They applied electro-pneumatic circuits and signal conditioning boards of sensors that helped to reach an optimized CPAP behavior. For instance, low energy loss can be achieved. Furthermore, the microcontroller achieved a significant enhancement to the functions of CPAP system hardware. This enhancement has been achieved because developed software application was used [19].

Meenu and Hariharan in 2015, demonstrated the position sensorless control of brushless DC (BLDC) motor that was applied in a CPAP device for sleep apnea disorder patients. It used back Electromotive Force (EMF) difference estimation approach. This system was designed in MATLAB/Simulink programming toolbox. A large number of CPAP devices contained a BLDC motor to operate the blower fan. This blower fan increased or decreased the airway pressure of patient's in response to their pattern of breath. It opened patient's airway during sleep when applied a flow of pressurized air inside the throat. Sensorless BLDC were perfect as sleep apnea equipment because the motor was never operated below the minimum threshold speed of the driver. Also, there was no sudden risk changed in load and it has a long lifetime that it was useful for medical devices. This system seems not to require any phasedelay circuit. Thereby the complexity of the system was cut down [20].

Tourgoli and Sedghisigarchi in 2016, designed and investigated the control from the electrical aspect of the CPAP device. An electrical motor drives the system that was optimal to be applied as a typical CPAP medical device. This device involves several steps. First, developed a MATLAB/Simulink model for the entire system consisted of the electrical and mechanical parts. Second, a closed-loop permanent magnet motor drive based on the Filed Oriented Control (FOC). It was implemented to produce the required and passed pressure to the patient in various patterns of breathing. FOC strategy included two control loops, (i) outer-loop (speed loop) and (ii) inner-loop (current loop). These loops produced fast dynamic response, stability of the entire system, and controllability of the system entirely. Last, the simulation of the outcomes showed an impressive dynamic usability for electric motor drive system performance under various patients' situations [21].

Senavongse et al. in 2016, developed and designed a prototype CPAP machine to have the useful functions to support patients who suffer from mild snoring trouble or the severe obstructive sleep apnea. This system included hardware design and control design. The CPAP machine has an Arduino microcontroller besides a 3-phased motor that allows the CPAP to be portable, small, and give harmonic air pressure. The outcomes of the test results showed that the measurement accuracy of moisture was $94.09 \%$, the temperature measurement accuracy was $99.20 \%$, while the pressure sensor has an accuracy of over $97 \%$. The CPAP machine produced comparable pressure to the ideal pressure values of CPAP backgrounds [22].

Scheel et al. in 2017, improved the closed-loop control on the CPAP device by using a model-based control method that involved a state-space controller, an I-controller, and pressure reference. These three elements introduced a model for the pneumatic section of the CPAP device and patient. The breathing effort of the patient was examined in a control strategy to provide an individual therapy. The simple 1 st order model handled resistance $\mathrm{R}$ of the upper airway, capacitance $\mathrm{C}$ of lung. The patient breathing effort showed a 2 nd order source of pressure. Additionally, the closed-loop control was optimized and modified reference improvement [23]. In the same year, the same researchers implemented a model-predictive control approach that included the patient's breathing effort calculation of the control variable and the patient individualized control strategy. Each one of the developed subsystems:

a) Four-stage cascade composed.

b) Parameterized with the pole-placement approach.

c) Model predictive control (MPC) approach.

The above subsystems were all simulated in MATLAB/Simulink with probability of a modelbased control approach. The pressure variation was reduced using MPC approach when the patient effort of breathing was considered. Furthermore, it produced an essential enhancement quality of the control [24].

Zhengjun et al. in 2017, designed a hardware circuit of the CPAP that showed the fundamental work of ventilator mechanism. After that, an Artificial Neural Network (ANN) algorithm was applied to the CPAP ventilator. This design realizes the intelligent control of respiratory flow, pressure, speed, and other variables. Subsequently, the property of the ventilator was tested and examined it with the international mainstream ventilators. The test results showed that the performance of the ventilator was reliable and stable. Therefore, the output pressure was flat and steady. Also, the respiratory triggering was sensitive, and the produced noise was low. The system offered a more relaxed breathing exercise and a much therapeutic effect of patients [25]. 
Amrulloh et al. in 2019, developed an on-demand CPAP controller (OCPAP). This system provides a predefined positive air pressure while the sleep apnea issue followed by the normal respiratory pressure through the non-apnea event. The model was designed by using Labview software. The OCPAP model included source air, regulating valve of pressure, PI controller, pressure sensor, mask, and tube. Signal of breathing was stimulated by using a modified sinus to model apnea event and normal breathing pattern. Although the system improved the breathing convenience of the patient, it is considered helpful those patients who planned to stop the need of using CPAP in the future [26].

Garmendia et al., in 2020, designed a low cost noninvasive bi-level pressure support ventilator (CPAP, BiPAP). It is easy-to-build to be used in low middle income countries. Also, it is useful in pandemic conditions. Particularly, these days where coronavirus pandemic imposed huge impact on people's lives. Besides it used with hospital strained conditions dealing with the season of influenza. The ventilator was constructed based on handy available materials in online stores .Its design system included (i) 2 pressure sensors, (ii) high-pressure blower, (iii) digital display, and (iv) an Arduino (Nano) controller.

The configuration details were shown as open source for replication. Its components are not built-in where if any component fails in the system it can be replaced easily. The ventilator design was compared and evaluated with commercial ventilator to enhance its efficiency. The pressure waveform shown from the prototype ventilator was similar to the pressure waveform observed in the commercial ventilator. Furthermore, the results after applying a prototype ventilator to humans showed their similarity to the bench test to ensure no-erroneous cycling or triggering events [27].

Table (1) presented the comparison table of the modern CPAP designed in terms of hardware, simulation, and control algorithm design.

Table (1): The comparison table of modern CPAP design

\begin{tabular}{|c|c|c|c|}
\hline \multirow{2}{*}{ Authors/year } & \multicolumn{3}{|c|}{ Methodology } \\
\hline & Hardware Design & Simulation Design & Control Algorithm \\
\hline $\begin{array}{c}\text { Xu et al. in } 2014 \\
\text { [13] }\end{array}$ & $\begin{array}{l}\text { Used a BLDC motor to drive the } \\
\text { blower }\end{array}$ & - & $\begin{array}{c}\text { Used a PID control, Pressure } \\
\text { evaluate correction module(PECM)- } \\
\text { PID control }\end{array}$ \\
\hline $\begin{array}{l}\text { Ximenes et al. in } \\
2014 \text { [19] }\end{array}$ & $\begin{array}{l}\text { Experimental prototype CPAP } \\
\text { hardware design included: } \\
\text { Sensors, valves, and } \\
\text { microcontroller. It designed for } \\
\text { neonatal intensive care unit }\end{array}$ & - & Two Microprocessors \\
\hline $\begin{array}{l}\text { Meenu and } \\
\text { Hariharan in } \\
2015[20]\end{array}$ & - & $\begin{array}{l}\text { Design a CPAP system used } \\
\text { MATLAB/Simulink } \\
\text { environment. } \\
\text { sensor less BLDC motor used } \\
\text { to drive the blower fan }\end{array}$ & PID control \\
\hline $\begin{array}{l}\text { Tourgoli and } \\
\text { Sedghisigarchi in } \\
2016[21]\end{array}$ & - & $\begin{array}{l}\text { The dynamic and control } \\
\text { CPAP system was modeled } \\
\text { in MATLAB/Simulink } \\
\text { environment. } \\
\text { a permanent magnetic motor } \\
\text { was used }\end{array}$ & $\begin{array}{l}\text { PID close loop control where its } \\
\text { parameters tuned with open loop } \\
\text { Bode-plot diagram used } \\
\text { MATLAB/Simulink. } \\
\text { a closed-loop permanent magnet } \\
\text { motor drive based on FOC included } \\
\text { two control loops, outer-loop for } \\
\text { speed and inner-loop for current }\end{array}$ \\
\hline $\begin{array}{l}\text { Senavongse et al. } \\
\text { in } 2016 \text { [22] }\end{array}$ & $\begin{array}{l}\text { developed and designed a } \\
\text { prototype CPAP machine to have } \\
\text { the coveted functions used to } \\
\text { support the patient has mild } \\
\text { snoring trouble the OSA }\end{array}$ & - & $\begin{array}{l}\text { The CPAP machine microcontroller } \\
\text { was an Arduino board Mega } 2560\end{array}$ \\
\hline $\begin{array}{l}\text { Scheel et al. in } \\
2017[23,24]\end{array}$ & - & $\begin{array}{c}\text { Four-stage cascade } \\
\text { composed, parameterized } \\
\text { with the pole-placement } \\
\text { approach, MPC approach, } \\
\text { these were all simulated in } \\
\text { MATLAB/Simulink }\end{array}$ & $\begin{array}{l}\text { The improved close loop model- } \\
\text { based control method involved a } \\
\text { pressure reference, state-space and I- } \\
\text { controller }\end{array}$ \\
\hline $\begin{array}{l}\text { Zhengjun et al. in } \\
2017 \text { [25] }\end{array}$ & $\begin{array}{l}\text { Design the hardware system used a } \\
\text { microcontroller with BLDC motor }\end{array}$ & - & $\begin{array}{c}\text { The artificial neural network. an } \\
\text { ANN breathing template with or } \\
\text { without PID control used to match } \\
\text { with the breathing mechanism } \\
\text { waveform }\end{array}$ \\
\hline
\end{tabular}




\begin{tabular}{|c|c|c|c|}
\hline $\begin{array}{c}\text { Amrulloh et al. in } \\
2019 \text { [26] }\end{array}$ & - & $\begin{array}{c}\text { Design a CPAP system used } \\
\text { a LabVIEW software }\end{array}$ & $\begin{array}{c}\text { on-demand CPAP controller was } \\
\text { implemented with } \\
\text { PI controller. }\end{array}$ \\
\hline $\begin{array}{c}\text { Garmendia et al., } \\
\text { in 2020 [27] }\end{array}$ & $\begin{array}{c}\text { Design a non-invasive ventilator } \\
\text { (CPAP, BiPAP), to improve its } \\
\text { efficiency, the design was } \\
\text { compared with commercial } \\
\text { ventilator. }\end{array}$ & - & Used Arduino NANO as controller \\
\hline
\end{tabular}

\section{Results of the Literature and Discussions:}

This section will deal with the results related to the research papers on modern CPAP devices. In addition, the discussion will explain the accuracy of experimental CPAP results compared with a commercial CPAP device and how the results coincide with the error ratio defined by FDA. The strategy followed in this section is to compare different papers in this regard is based on the classification of the CPAP devices into (i) hardware design (the criteria used to evaluate the papers belong to this category are number of components used in the design that determine the cost of constructing a single device), (ii) Simulation based CPAP system (from the software engineering point of view the comparison of MATLAB/Simulink and LabVIEW software will be highlighted in terms of ease of use and simulation), (iii) control algorithm (this category can be classified as Model Predictive Control (MPC), Proportional Integral Derivative (PID) control, Artificial Neural Network (ANN) control), (vi) the last category involved in this survey can be classified as those papers whose performance is measured according to the accuracy. The accuracy is calculated according to pressure value recorded. The other subcategory depends on the predefined FDA-based threshold value in which it considers this value as a reference. This strategy of classification is shown in Figure (3).

\subsection{Hardware Design}

From this comparison, the main aim is to approve the prosperity of using cheaper components (sustainable component whose outcomes might be comparable or might be even better than those using the traditional hardware components. Here, the discussion of components used is presented in this section. All the papers considered in this section deal with the hardware design of CPAP device.

In [13], the authors designed a model system of ventilator CPAP for OSA patients. The circuit component contains complicated and huge electronic items to build up the model. A MEGA16A microprocessor chip was used as a controller. This microprocessor had $1 \mathrm{~KB}$ SRAM and $16 \mathrm{~KB}$ programmable flash. Furthermore, it had 10 bit Analog to Digital Converter (ADC) with a voltage range from $[0-5 \mathrm{~V}]$. The complexity of this circuit might be increased when it has more items such as a couple of Amplifiers used to amplify the signal. Also, there were some problems with how to connect the microprocessor with USB to the Personal Computer (PC) because of the lack of one component to be adopted in the circuit such as USB-UART-BRIDGE. However, a good choice of the three-phase BLDC motor in a medical device achieves a noiseless operation, compact size, high-power factor, reliability, low-maintenance cost, and good efficiency [28]. The experimental test of CPAP is based on changing of various pressure values and calculating the PWM where this value is used to generate the analog output without need to adopt a Digital Analog Converter (DAC) via the circuit. The design showed an error ratio of about $\left(0.5 \mathrm{cmH}_{2} \mathrm{O}\right)$ merely when tested experimentally. This design is not tested with real patients to show its performance for treatment. It is just tested to show the ability of microprocessor to control the motor speed and the pressure value delivered to the patient.

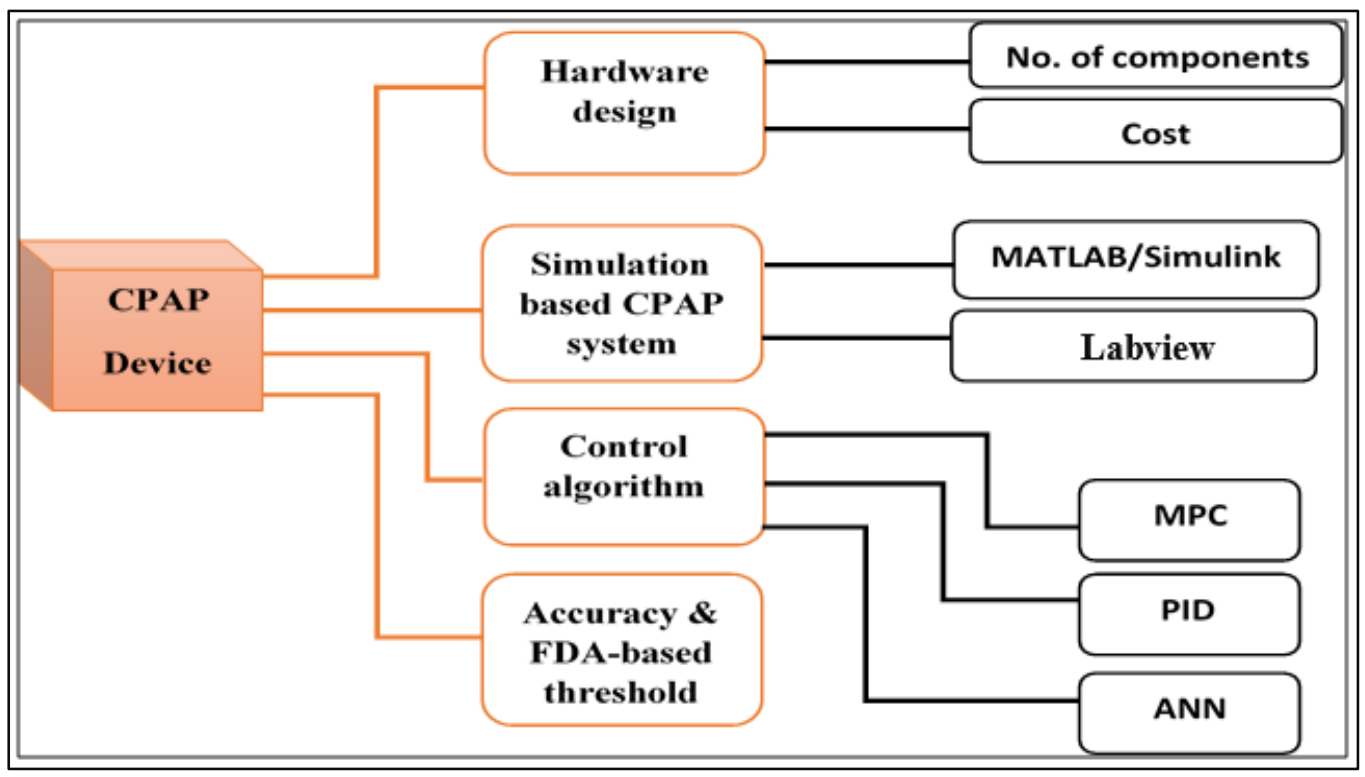

Figure (3): The strategy of classification of the CPAP system. 
While in [19], the authors designed a ventilator CPAP device for OSA cases used in NICU. The design input are consisted of air with Oxygen and the output is a humidity air delivered to the neonatal. Therefore, the included components are valves, two items of the microcontroller (M430G2553), sensors, operation amplifier, and instrumentation amplifier. Both items of the microcontroller (M430G2553) are used to convert Analog results to digital form in order to easily read and analyze the obtained results in the software. The part of a circuit that is responsible for operating these two microcontrollers was a valve's opening/closing to send the final required value to the sensor. Additionally, the microcontroller used to send an alarm when any error occurs. This model has been designed in such way in order to provides safety to infants' case. Therefore, the values set by the operator will be clear and quick to the microcontroller. Even Though, the size of microcontroller is small and it is cheaper than Arduino or any other microprocessor, it is difficult to obtain this microcontroller chip nowadays. In addition, it is difficult to be programmed and also it needs other helping components to achieve its goal. The use of these extra components would make the cost of the model to be increased.

The designer had a difficulty choosing the sensors as well as calibrating them. Moreover, the designer had difficulty in analyzing the power supply condition. The device model simulation was coded in MATLAB environment to test its performance. The simulation results were not enough for arbitration for infants' safety. Therefore, the reliability tests were inevitable when it was used with infants. The safety condition would not be reliable validated unless testing the model with real cases. This design achieved cheaper and easy to use CPAP device. However, the system design was complicated and not proven to be safe to use for infants due to aforementioned reasons (Figure4).

Figure (4) shown the relationship between the pressure values with the analog voltage values, and digital values of PWM ratio. In fact, the PMW represents the percentage of the operating voltage. Both graphs obtained from the equation mentioned in [12][19].

$V_{\text {out }}=0.0054 p+0.1703$

$V_{\text {out }}=0.00 p^{2}+0.0054 p+0.1007$

$V_{\text {out }}=0.0000 p^{3}+0.0000 p^{2}+0.0051 p+0.1715$

$\operatorname{PWM}(P)=8.76 \times 10^{-5} \times P^{2}+0.0078 \times P+1.966$

It can be observed from figure (4a) that the relationship between the pressures measured by $\mathrm{cmH}_{2} \mathrm{O}$ and PWM, it is a non-linear relationship represented by a curve that started from $3 \mathrm{cmH}_{2} \mathrm{O}$ and ended at $20 \mathrm{cmH}_{2} \mathrm{O}$. When it comes to PMW we noticed that there is also an increase of these values when the pressure values increased, i.e. when the pressure value almost $3 \mathrm{cmH}_{2} \mathrm{O}$ as can be clearly seen in the figure the PMW value was 78. At the same time the PMW value become 412 when the pressure value equaled $20 \mathrm{cmH}_{2} \mathrm{O}$. On the other hand, by looking at figure (4b), it can be emphasized that the relationship between each of the output voltage and pressure is linearly increasing. Thus, when the pressure value increases, we realize that the output voltage increases accordingly. From both figures ( $4 \mathrm{a}$ and $4 \mathrm{~b})$ it can be assumed that an ability to control the pressure as a function of voltage and the speed of motor.

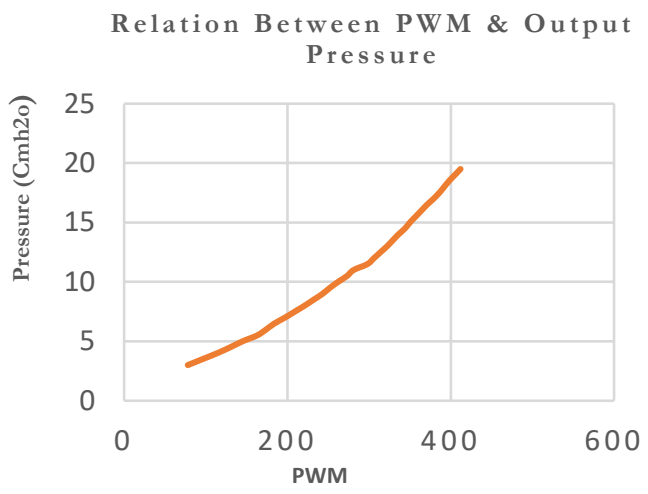

(A)

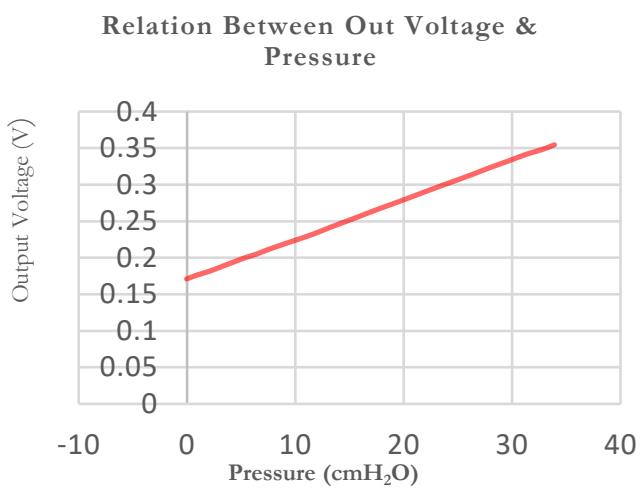

(B)

Figure (4): The relation between pressures with; (A) PWM, (B) Voltage.

In contrast to the work presented in[12][19], the work presented in [27], proposed a design of CPAP ventilator for acute or chronic respiratory failure. Here the design is less complex and easier than that presented in [12], [19] due to the availability of the components online. Moreover, the main controller was Arduino Nano board that is well-known of its easy programming with $\mathrm{C}++$ language in Arduino IDE. The Arduino IDE possesses all required codes to programing the various types of sensors. As this model's architecture is not complicated as compared with previous models mentioned in this section, its components can easily be replaced. The design was tested in two phases. The first phase, conducted in terms of testing device with simulation lung model for obstructive and restrictive or both. The second phase was conducted in terms of testing the device with 12 healthy volunteers. The test results compared with commercial CPAP device. The pressure waveform shown from the prototype ventilator was similar to the pressure waveform observed in the commercial ventilator. Finally, this model validated its safety to be used with respiratory disorder diseases. It was approved to be lower cost than all other models in about less than $75 \$$. 


\subsection{Simulation Based CPAP System}

In this section comparison of several the academic works has been presented in terms of the software used to simulate the design of CPAP. The MATLAB and LabVIEW are used for this purpose. The criteria used in this comparison is based on the complexity and the expertise required to simulate the design. From a software engineering point of view the comparison of both software will be taken into account. In [20], the authors designed a CPAP system used MATLAB/Simulink environments with a sensorless position as a control for BLDC motor. A subsystem of each CPAP component was made to simulate the entire system of CPAP such as: mask, tube, and motor drive. A zero crossing point (ZCP) of different back EMF was designed to represent a sensorless BLDC motor in this design. Thus, a delay circuit was not required for motor design. The simulated breathing signal was adopted as an input parameter to the CPAP model. The CPAP system is designed with a sensorless BLDC motor to prevent motor operation under the lower threshold speed. On the other hand, the sensorless BLDC motor is important to be present in the design to enhance the performance of CPAP. This will make CPAP useful with OSA patients and improved patient safety.

Similarly, in [21], the MATLAB/Simulink was used for simulation-based CPAP and BiPAP main operation condition. Unlike the work presented in [20], in [21] a permanent magnet motor with FOC control algorithm was used. The benefit of using a permanent magnet motor is has a higher efficiency and higher power to weight ratio. This simulation might guide the designer during the steps of constructing the CPAP device in reality to choose the size, flow, and pressure of the fan/blower. Furthermore, this system is designed to be flexibly used with different patient's breathing conditions.

When it comes to the work presented in [26], the CPAP system simulation was designed with LabVIEW software program. This system provided a predefined positive air pressure while the sleep apnea issue followed by the normal respiratory pressure through the non-apnea event. This design showed accuracy of one hundred percent for the detection of sleep apnea disorder. In order to achieve that design in reality with real patients, it requires more development to approve its robustness. The advanced software programs nowadays are actively used in simulation and modeling. To evaluate which programming is most suitable for simulation, MATLAB outperform the LabVIEW. MATLAB/Simulink has been commonly used to simulate motors, control and circuits, etc... Anyone had a programming background in MATLAB/Simulink would observe that the simulation in MATLAB compared to LabVIEW is not complex. Assuming simulation time/loop, despite of the fact that LabVIEW runs faster than MATLAB/Simulink for limited number of loops, MATLAB/Simulink performs better with an increasing number of loops [29]. It's worth mentioning, if the designer has limited expertise in programming and is slightly familiar with simulation design or control algorithms, then LabVIEW would be more convenient to learn. In fact, both designs in MATLAB and Lab give good expression to the simulation of CPAP device and depend on the prior knowledge of designer in a programming environment.

\subsection{Control Algorithm}

This section deals with different control approaches. The discussion handles explanation which of these approaches might improve CPAP performance. It also explain the rate of patients' responses to the pressure value delivered to them according to the outcomes obtained in papers [11][24][25] where PID, MPC, and ANN were used respectively as controllers in system design to ensure good performance of CPAP.

The PID control is offering the most efficient solution too different real world control problems. A PID controller might be assumed as an extreme form of a phase lead lag compensator with one-pole at the origin and the other pole at infinity. The transfer function is expressed in parallel form given by equation (5) or the typical form expressed by equation (6)

$$
\begin{aligned}
& \text { (1) } \mathrm{G}(\mathrm{s})=K_{P}+K_{I} \frac{1}{s}+K_{D} \mathrm{~s} \\
& \text { (2) } \mathrm{G}(\mathrm{S})=K_{P}\left(1+\frac{1}{s T_{I}}+T_{D} \mathrm{~s}\right)
\end{aligned}
$$

Where $K_{P}, K_{I}, K_{D}, T_{I}$, and $T_{D}$ are the proportional gain, the integral gain, the derivative gain, the integral time constant and, the derivative time constant respectively [30].

The MPC control, it is an advance and important control technique for complex multivariable control problems. The fundamental MPC idea paraphrased as follows. Assume that multiple inputs and multiple output processes are needed to control while performing variation constraints on the input and output variables. The model and current measurements could be utilized to guess future values of the outputs if a sensibly defined dynamic model of the process is available. Then the appropriate changes in the input variables could be computed according to both measurements and predictions. Essentially, the variation in the single input variables are coordinated after taking in account the input and output relationships designed by the process model [31].

The ANN is a powerful and resilient machine learning technique. ANN mimics human intellect. Input / output signals are send from input to output nodes. Artificial neural networks are analog the human brain in preparing input signals and convert them into output signals. ANN is a type of non-parametric modeling method, which is convenient for complex phenomena that investigators as a black box. ANN can learn from data without particular functional presumptions [32].

The [11][24][25], all of these research papers introduced a different control algorithms. The first one deals with PID control. The design of the CPAP device with this type of controller, aimed to sustain the therapeutic pressure and reduce pressure fluctuations during spontaneous breathing. The commonly CPAP device deal with PID that related to how this controller 
ease to tune its parameters in terms of using Ziegler \& Nichols approach, bode-plot, pole placement, and etc... The basic configuration of PID control can be designed in reality or simulation using MATLAB/Simulink. Nowadays, due to the tremendous developments in the medical industry, the use of unconventional control methods is both an accomplishment and a challenge to design a medical device that assists patient.

The second one deals with MPC approach. As previously defined about model predictive control, it was used with multivariable. Thus, the patient effort considered due to the control parameters to improve control quality and patient's individualized control. The model based control with pole placement method is simulated first using Simulink then a MPC control used to reduce the criterion of the given quality. The design with MPC needs more practice of its simulation and iteratively examined its control quality again and again. CPAP with MPC control is trained in a simulated environment, and this type of control demands a repetitive examination process in order to achieve the best results.

The last one deals with artificial neural network to design an intelligent ventilator of rational price and supreme performance throughout cost management. The mask-dropped-off, this controller sends warning signals to set the ventilator at stop-mode. ANN designed with two layers, one for recognition and the other for compare. In [25], the ANN template dimension was 10X10, that means a hundred types of breathing waveforms stored in it. The ANN template included normal breathing and disorder breathing waveforms. The ventilator design was tested in to bimodes, CPAP mode and Auto-CPAP. A comparison of the test results with a commercial ventilator was made. The test results showed that the performance of the ventilator was reliable and stable. Therefore, the output pressure was flat and steady. Also, the respiratory triggering was sensitive, and the produced noise was low. The system offered a more relaxed breathing exercise and a much therapeutic effect of patients. The error ratio was about $\pm 0.4 \mathrm{cmH}_{2} \mathrm{O}$ complies with standard error ratio of about $\pm 2 \mathrm{cmH}_{2} \mathrm{O}$. The noise value was about $42 \mathrm{~dB}$ that complies the condition of standard background value of $39 \mathrm{~dB}$ and should not pass it above $6 \mathrm{~dB}$. The device with ANN controller is examined with a real patient, it returned good results in terms of controlling the flow during the inhalation process. Additionally, the patient felt more comfortable during the use of this intelligent ventilator. Figure (5) shows a pressure release waveform of one volunteer patient during the application of intelligent ventilator.

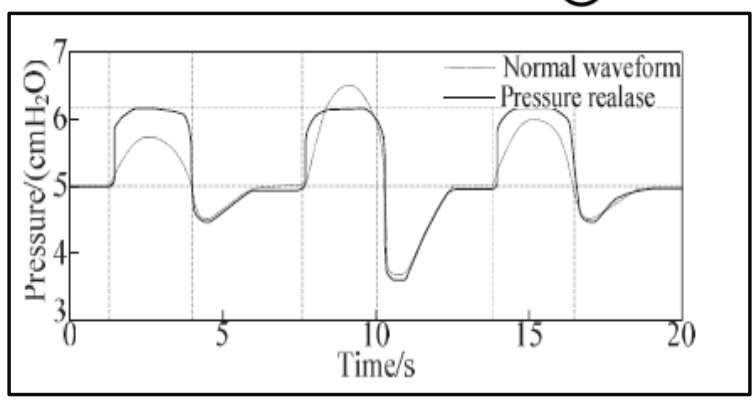

Figure (5) Patient's pressure release waveform [25].

As shown in figure (6), the waveform appears to be more flat and smooth as compared with the normal waveform. Thanks to the usage of ANN in the industry of CPAP devices, a good outcome was obtained in comparison with the previous two control approaches PID and MPC. The only issue that could be challenging is to utilize ANN in the situation that the incoming input values are not identical to the sensor readings. In this case, a new node needs to be added in the ANN template to get a new ANN template that matches the input mode.

\subsection{Accuracy and FDA-based Threshold Value}

This section deals with the accuracy percent value used to evaluate the performance of the CPAP design and the FDA-based threshold value of different CPAP devices to distinguish which of these designs comply with the threshold value and achieves more reliable situations of CPAP treatments. As for the accuracy, the authors in [22], examined the accuracy of sensor readings and comparing them with the ideal settings of the CPAP device. The pressure sensor was considered as a significant measurement. Therefore the pressure sensor accuracy measured of over $97 \%$. This accuracy compared with ideal setting of CPAP. The design that was presented in the paper showed its reliable performance to be used as a prototype device for snoring person whom might have OSA. The ideal setting of CPAP pressure of about $1 \mathrm{cmH}_{2} \mathrm{O}$ of $10 \mathrm{~kg}$ of the body weight, e.g. $7 \mathrm{~cm} \mathrm{H}_{2} \mathrm{O}$ of $70 \mathrm{~kg}$ patient (ranging 7 to $15 \mathrm{~cm} \mathrm{H}_{2} \mathrm{O}$ ) [33].

In [26], the authors showed accuracy of $100 \%$ for the detection of sleep apnea event in signal to operate CPAP in this case. The purpose of this paper to design CPAP device delivered pressure to a patient in apnea event and obstruct pressure during normal breathing. The $100 \%$ accuracy was achieved with simulation design of CPAP device in Labview environment with a synthetic data of breathing signal conducted by the researcher to clarify normal, hypopnea, and apnea breathing pattern. The accuracy might be less than $100 \%$ with a condition change e.g. the design implanted in reality with real patient breathing pattern.

For the FDA-based threshold value, the $[10][11][12][25]$ all deal with the error ratio of pressure results allowed by the FDA criteria of a limit range $\pm 2 \mathrm{cmH}_{2} \mathrm{O}$. The $\pm 1 \mathrm{cmH}_{2} \mathrm{O}, \quad \pm 1.5 \mathrm{cmH}_{2} \mathrm{O}$, $<0.5 \mathrm{cmH}_{2} \mathrm{O}$, and $\pm 0.4 \mathrm{cmH}_{2} \mathrm{O}$ respectively as presented in the introduced papers above. These values differ from one another in terms of the data used of patient breathing patterns simulation or real voluntary patients. In addition, depend on the components used to design a CPAP device with a 
control algorithm used. Also, the differences depend on the real design of CPAP device or the use of a software program to simulate the CPAP device. All these prior conditions might be affected by the value of the error ratio. The best and near error ratio obtained about $\pm 0.4 \mathrm{cmH}_{2} \mathrm{O}$. In this paper, an intelligent ventilator device is designed and tested with real patient. This design showed good performance and a deeper error ratio of different pressure results. Table (2) shows the FDA-based threshold value of these research papers.

Table (2): The research papers deal with the FDA-based threshold value

\begin{tabular}{|c|c|c|c|c|c|}
\hline \multirow[b]{2}{*}{ No. } & \multirow[b]{2}{*}{ Authors/year } & \multirow[b]{2}{*}{ Methodology } & \multirow[b]{2}{*}{ Data specimen } & \multicolumn{2}{|c|}{ FDA Value } \\
\hline & & & & $\begin{array}{c}\text { FDA criteria of } \\
\text { CPAP pressure } \\
\text { value } \\
\end{array}$ & $\begin{array}{l}\text { FDA-based } \\
\text { threshold value }\end{array}$ \\
\hline 1 & $\begin{array}{l}\text { Tsai et al. in } \\
2008 \text { [10] }\end{array}$ & $\begin{array}{l}\text { The blower was driven by a } \\
\text { brushless DC motor that directly } \\
\text { controls the air for the patient. The } \\
\text { informed control method simply } \\
\text { was implemented guided by a low- } \\
\text { cost microcontroller or digital } \\
\text { signal processor. }\end{array}$ & $\begin{array}{c}\text { Artificial lung } \\
\text { simulator and respirator } \\
\text { monitor to display the } \\
\text { data }\end{array}$ & & $\pm 1 \mathrm{cmH}_{2} \mathrm{O}$ \\
\hline 2 & $\begin{array}{l}\text { H. and Zheng- } \\
\text { Long in } 2012 \\
\text { [11] }\end{array}$ & $\begin{array}{l}\text { Commercially available CPAP } \\
\text { devices compared with } \\
\text { experimental CPAP device. }\end{array}$ & $\begin{array}{l}\text { Collect a data from } \\
\text { breath cycle of } 6 \\
\text { subjected ( } 2 \text { patient } \\
\text { with apnea and } 4 \\
\text { healthy subjects) used } \\
\text { ventilator Analyzer } \\
\text { Exhalation and sent } \\
\text { them to the PC } \\
\text { monitor. }\end{array}$ & $\pm 2 \mathrm{cmH}_{2} \mathrm{O}$ & $\pm 1.5 \mathrm{cmH}_{2} \mathrm{O}$ \\
\hline 3 & $\begin{array}{l}\text { Min Dai et al. } \\
\text { in } 2013 \text { [12] }\end{array}$ & $\begin{array}{l}\text { Design a CPAP system with PID } \\
\text { control and smart motor drive, used } \\
\text { a MEGA16A module controller }\end{array}$ & $\begin{array}{l}\text { Raw data entered from } \\
\text { keyboard of the device }\end{array}$ & & $<0.5 \mathrm{cmH}_{2} \mathrm{O}$ \\
\hline 4 & $\begin{array}{l}\text { Li et al. in } 2017 \\
{[25]}\end{array}$ & $\begin{array}{l}\text { Design the hardware system used a } \\
\text { microcontroller with BLDC motor } \\
\text { with the artificial neural network. } \\
\text { an ANN breathing template }\end{array}$ & $\begin{array}{c}\text { Test lung } \\
\& 5 \text { volunteers with } \\
\text { OSA diseases }\end{array}$ & & $\pm 0.4 \mathrm{cmH}_{2} \mathrm{O}$ \\
\hline
\end{tabular}

\section{Conclusion:}

In this paper, we reviewed the CPAP medical device design methods. The designs were developed to treat respiratory disorders such as COVID-19 and OSA patients. In the discussion of each design, its pros and possible cons are also discussed. This paper is one of the few papers that aims to overview CPAP system in terms of the design and its control algorithms. We noticed that the evaluated of CPAP performance depended on the several elements such as, the control algorithms are used and the data of breathing pattern that are used to represent the patient COVID-19 or OSA disorders. The components are used to design the CPAP system in terms of microprocessor or motors also effected on CPAP performance. The reliable and stable results of CPAP pressure achieved when its accuracy is convincing and the error ratio of pressure results allowed by the FDA criteria of a limit range $\pm 2 \mathrm{cmH}_{2} \mathrm{O}$. The performance of the CPAP device increase when the pressure error ratio is lower than the standard ratio. The intelligent ventilator device showed good performance and a deeper error ratio of different pressure results. The CPAP has proved its effectiveness in treating patients with respiratory disorders throughout the studies presented.

\section{References:}

[1] A. R. Ramos et al., "Obstructive sleep apnea phenotypes and markers of vascular disease: A review," Front. Neurol., vol. 8, no. DEC, pp. 1-6,
2017, doi: 10.3389/fneur.2017.00659.

[2] M. Friedman and O. Jacobowitz, "Sleep apnea and snoring: Surgical and non-surgical therapy," in Sleep Apnea and Snoring: Surgical and Non-Surgical Therapy, 2019, p. 3.

[3] H. Ouassou et al., "The Pathogenesis of Coronavirus Disease 2019 (COVID-19): Evaluation and Prevention," J. Immunol. Res., vol. 2020, no. July, pp. 1-8, 2020, doi: 10.1155/2020/1357983.

[4] S. P. Adhikari et al., "A scoping review of 2019 Novel Coronavirus during the early outbreak period: Epidemiology, causes, clinical manifestation and diagnosis, prevention and control," pp. 1-12, 2020, doi: $10.21203 /$ rs.2.24474/v1.

[5] R. G. S. de Andrade, V. S. Piccin, J. A.

Nascimento, F. M. L. Viana, P. R. Genta, and G. Lorenzi-Filho, "Impact of the type of mask on the effectiveness of and adherence to continuous positive airway pressure treatment for obstructive sleep apnea," Jornal Brasileiro de Pneumologia, vol. 40, no. 6. pp. 658-668, 2014, doi: 10.1590/S1806-

37132014000600010 .

[6] C. Carter, H. Aedy, and J. Notter, "COVID-19 disease: Non- Invasive Ventilation and high frequency nasal oxygenation," Clin. Integr. CARE, no. №07/2, pp. 159-161, 2020, doi: 10.37882/22232982.2020.07-2.23.

[7] T. L. Giles, T. J. Lasserson, B. J. Smith, J. White, J. Wright, and C. J. Cates, "Continuous positive airways pressure for obstructive sleep apnoea 
in adults: A Cochrane Collaboration Review," Cochrane Database Syst. Rev., no. 1, pp. 1-15, 2006.

[8] S. Ashaat and A, "understanding upper air way dynamic characteristics in osa patient under invasive and non invasive treatment.pdf," 2016.

[9] A. Bachour, H. Avellan-Hietanen, T. Palotie, and P. Virkkula, "Practical Aspects of Interface Application in CPAP Treatment Adel," Hindawi Can. Respir. J., pp. 1-9, 2019.

[10] C. C. Tsai, Z. C. Wang, and C. S. Chen, "Two degree-of-freedom control for bi-level positive airway pressure of an obstructive sleep apnea treatment system," IECON Proc. (Industrial Electron. Conf., vol. 31, no. 6, pp. 944-949, 2008, doi:

10.1109/IECON.2007.4460146.

[11] Z.-Y. H. and H.-D. D. Zheng-Long Chen, "Control system design for a continuous positive airway pressure ventilator," Biomed. Eng. Online, pp. 113, 2012.

[12] D. Y. Min Dai, Zhisheng Zhang, Zhigang Liu, "Control Module Design for a Continuous Positive Airway Pressure Ventilator," vol. 321, no. 324, pp. 1657-1661, 2013.

[13] Y. Xu, L. Li, J. Yan, and Y. Luo, “An Optimized Controller for Bi-level Positive Airway Pressure Ventilator," nternational Conf. Futur. Comput. Commun. Eng., pp. 149-152, 2014, doi: 10.2991/icfcce-14.2014.37.

[14] C. McDaid et al., "A systematic review of continuous positive airway pressure for obstructive sleep apnoea-hypopnoea syndrome," Sleep Med. Rev., vol. 13, no. 6, pp. 427-436, 2009, doi: 10.1016/j.smrv.2009.02.004.

[15] G. Labarca, J. Dreyse, L. Drake, J. Jorquera, and F. Barbe, "Efficacy of continuous positive airway pressure (CPAP) in the prevention of cardiovascular events in patients with obstructive sleep apnea: Systematic review and meta-analysis," Sleep Med. Rev., vol. 52, p. 101312, 2020, doi: 10.1016/j.smrv.2020.101312.

[16] C. E. Sullivan, M. Berthon-Jones, F. G. Issa, and L. Eves, "Reversal of Obstructive Sleep Apnoea By Continuous Positive Airway Pressure Applied Through the Nares," Lancet, vol. 317, no. 8225, pp. 862-865, 1981, doi: 10.1016/S0140-6736(81)92140-1. [17] B. A. and G.Iotti, "Continuous Positive Airway Pressure,” Springer-Verlag Berlin Heidelb., pp. 53-70, 1991.

[18] F. Lofaso*, L. Heyer*, A. Leroy**, H. Lorino*, and D. I. A. Harf*, "Do turbines with servocontrolled speed improve continuous positive airway pressure generation?," CERS Journals Ltd 1994 Eur. Respir. Journ, vol. 0903, no. 1936, pp. 2077-2081, 1994.

[19] H. S. C. Mileny Ximenes Oliveira*, Amilton dos Reis Capistrano, Suélia de Siqueira Rodrigues Fleury Rosa, José Felício Silva, Adson Ferreira da Rocha, "Control system for continuous positive airway pressure,” vol. 30, no. 2, pp. 102-113, 2014.

[20] M. M. Meenu and S. Hariharan, "Position sensorless control of BLDC motor in continuous positive airway pressure device," 2015 Int. Conf. Control. Commun. Comput. India, ICCC 2015, pp. 230235, 2015, doi: 10.1109/ICCC.2015.7432897.
[21] M. Tourgoli and K. Sedghisigarchi, "Dynamic modeling and simulation of Continuous Positive Airway Pressure device," 2016 Int. Symp. Power Electron. Electr. Drives, Autom. Motion, SPEEDAM 2016, pp. 1441-1447, 2016, doi: 10.1109/SPEEDAM.2016.7525865.

[22] A. R. Wongwit Senavongse*, Phanuwat Boonchoo, Naruemon Nimitsantiwong, "Design and Development of Continuous Positive Airway Pressure Machine for Snoring," Biomed. Eng. Int. Conf., 2016.

[23] ** T. Schauer ** A. Berndt *** O. Simanski * M. Scheel *, "Model-based control approach for a CPAP-device considering patient's," IF AC Pap., vol. 50, no. 1, pp. 9948-9953, 2017.

[24] M. Scheel, A. Berndt, and O. Simanski, "Model predictive control approach for a CPAP-device," Curr. Dir. Biomed. Eng., vol. 3, no. 2, pp. 313-316, 2017, doi: 10.1515/cdbme-2017-0065.

[25] Z. Li, M. Zhang, and M. Du, "The study of intelligent control algorithm in CPAP ventilator," Proc. - 2017 Chinese Autom. Congr. CAC 2017, vol. 2017-Janua, pp. 386-391, 2017, doi:

10.1109/CAC.2017.8242797.

[26] Y. A. Amrulloh, B. A. Hisif, and D. A. R. Wat, "Development of On-Demand Controller for Continuous Positive Airways Pressure," Int. Conf. Mechatronics, Robot. Syst. Eng., pp. 20-23, 2019. [27] O. Garmendia et al., "Low-cost, easy-to-build noninvasive pressure support ventilator for underresourced regions: open source hardware description, performance and feasibility testing," Orig. Artic. Respir. INTENSIVE CARE, vol. 55, pp. 1-11, 2020.

[28] H. S. Hameed, "Brushless DC motor controller design using MATLAB applications," 1st International Scientific Conference of Engineering Sciences - 3rd Scientific Conference of Engineering Science, ISCES 2018 -

Proceedings, vol. 2018-Janua. pp. 44-49, 2018, doi: 10.1109/ISCES.2018.8340526.

[29] T. Tašner, D. Lovrec, F. Tašner, and J. Edler, "Comparison of LabVIEW and MATLAB for scientific research," Annals of the Faculty of Engineering Hunedoara, vol. fasc 3, no. tome 10. pp. 389-394, 2012.

[30] Y. (2005) Ang, K.H. and Chong, G.C.Y. and Li, "PID Control System Analysis, Design," IEEE Trans. Control Syst. Technol., vol. 13, no. 4, pp. 559-576, 2005. [31] F. j. Seborg, Dale E.; Edgar, Thomas F.; Mellichamp, Duncan A.; Doyle III, Process Dynamics and Control fourth edition, vol. 53, no. 9. 2019.

[32] Z. Zhang, "A gentle introduction to artificial neural networks," Ann. Transl. Med., vol. 4, no. 19, pp. 1-6, 2016, doi: 10.21037/atm.2016.06.20.

[33] D. by the E. based on information provided by B. \& D. H. W. thanks to Dr and E. D. Matthew Bragg, "No Title," Non-invasive ventilation device settings: a brief guide, 2013.

https://www.aci.health.nsw.gov.au/_data/assets/p df_file/0007/273553/non-invasive-ventilationdevice-settings-a-brief-guide-endorsed-29-august2013.pdf. 